\title{
Isolated Tumor Cells
}

National Cancer Institute

\section{Source}

National Cancer Institute. Isolated Tumor Cells. NCI Thesaurus. Code C106301.

The presence of single tumor cells or tiny clusters of tumor cells in a pathologic specimen. 